\title{
Obesity: Open Access
}

\section{Examination of the Impact of Maternal Weight Gain on Abnormalities of Fetal Growth in Women of Varying Body Mass Indices}

\section{Kristin Magner ${ }^{1}$, Sara Kritzer ${ }^{2}$ and Carri R Warshak ${ }^{3 *}$}

${ }^{\prime}$ Department of Obstetrics and Gynecology, The Christ Hospital, Cincinnati, OH, USA

${ }^{2}$ Department of Obstetrics and Gynecology, Northwestern University of Feinberg School of Medicine, Chicago, IL, USA

${ }^{3}$ Department of Obstetrics and Gynecology, Division of Maternal Fetal Medicine, University of Cincinnati College of Medicine, Cincinnati, OH, USA

*Corresponding author: Carri R Warshak, MD, Associate Professor, Department of Obstetrics and Gynecology, Division of Maternal Fetal Medicine, University of Cincinnati College of Medicine, 231 Albert Sabin Way, Cincinnati, OH 45267-0526, USA, Tel: 513 558-8448; Fax: 513 558-9820; E-mail: eaglercr@ucmail.uc.edu
Received date: 30 October 2015; Accepted date: 23 Nov 2015; Published date: 26 Nov 2015.

Citation: Magner K, Kritzer S, Warshak CR (2015) Examination of the Impact of Maternal Weight Gain on Abnormalities of Fetal Growth in Women of Varying Body Mass Indices. Obes Open Access 1(3): http://dx.doi.org/10.16966/2380-5528.112

Copyright: (C) 2015 Magner K, et al. This is an open-access article distributed under the terms of the Creative Commons Attribution License, which permits unrestricted use, distribution, and reproduction in any medium, provided the original author and source are credited.

\begin{abstract}
Objective: To analyze the association between maternal weight gain and abnormalities of fetal growth.

Methods: We calculated mean weight gain in pregnancies resultingin small for gestational age (SGA) or large for gestational age (LGA) fetuses, with normal growth as the referent. We classified pregnancies as to whether they had met, gained under or exceeded 2009 Institute of Medicine recommendations (IOMR) and evaluated the rate of SGA and LGA. Multivariateand linear regression analyses were performed.

Results: We found similar weight gains in women with normal versus SGA fetuses, 10.5 versus $9.6 \mathrm{~kg}$ respectively, LGA fetuses had a significantly higher weight gain, $13.8 \mathrm{~kg}(\mathrm{p}<0.01)$. We found higher rates of SGA in NW women who gained under versus met IOMR (17.5 versus $11.6 \%$ ), but not in OW women (10 versus $12 \%, p=0.58$ ). Obese women had a higher rate of SGA when women gained under versus met IOMR ( 10.7 vs $5.0 \%, p=0.02)$, however once controlled for confounders, this association was no longer significant, aOR 1.23 (0.82-1.86). The rate of SGA in obese women who gained under IOMR, $10.7 \%$, was less than the baseline risk of SGA in NW women, $11.6 \%$,indicating loss of a protective effect in obese women.

Conclusion: Weight gain in women who deliver normal weight fetuses and SGA fetuses is clinically similar, however in NW women there is a greater rate of SGA when weight gain is insufficient. This increase in SGA is not found in OW women, nor is it found in obese women, when adjusted for confounding variables. Any increase in SGA in obese women when they gain under IOMR appears to be secondary to a loss of a protective effect.
\end{abstract}

Keywords: Maternal weight gain; Fetal growth; Body mass index

\section{Introduction}

Obesity has reached epidemic proportions in the United States and has now been classified as a "disease" by the American Medical Association [1]. One third of women are obese and one half of pregnant women are obese or overweight [2]. The IOMR for maternal weight gain were revised in 2009, with an increased focus on maternal health (Table 1) [3]. Consequences of excessive weight gain are established. Several studies have demonstrated increases in macrosomia, diabetes, preeclampsia, cesarean delivery and adverse maternal and neonatal outcomes with excessive weight gain [4-10]. In addition, other studies have demonstrated that limited weight gain in obese and overweight women can reduce the risk of some pregnancy comorbidities such as gestational diabetes, preeclampsia, and operative delivery) [11-13]. However, consequences of limited weight gain are undetermined, especially in the obese. The known associations between limited maternal weight gain in pregnancy and SGA have driven continued recommendations regarding weight gain in pregnancy. However, whether the overweight and obese have increased rates of SGA when there is limited maternal weight gain is understudied. For this reason, the IOM called for additional research in the morbidly obese to help determine recommendations for weight gain in this population.

Previous studies have demonstrated an increase in SGA in women who gain insufficient weight, most of which were performed prior to the new IOM guidelines [13-16]. Most recently a secondary analysis from the NICHD MFMU network preeclampsia prevention trial reported on obstetrical outcomes with weight gain below the new IOMR. The multivariate analysis from this study obtained inconsistent results when evaluating whether weight gain under the IOMR increased the rate of SGA, with trends toward an increased risk in normal and obese women, but not in underweight or overweight women [9]. Two other studies have also examined the relationship between maternal weight gain and birth weight according to the 2009 IOMR specifically in the obese population $[17,18]$. Bodner et al. [18] studied a cohort of obese women, with those gaining within IOMR the referent and found increasing SGA with inadequate weight gain. Vesco et al. [17] also studied a cohort of obese women only with similar results. However, no studies have examined the rate of SGA in obese women, using the baseline risk of SGA in the population as the referent.

\begin{tabular}{|c|c|}
\hline BMI Category & Recommended weight gain (lbs) \\
\hline $18.5-24.9$ & $25-35$ \\
\hline $25.0-29.9$ & $15-25$ \\
\hline$>30$ & $11-20$ \\
\hline
\end{tabular}

Table 1: Institute of Medicine recommendations for maternal weight gain in pregnancy, revised in 2009. 
Establishing consequences of inadequate weight gain in pregnancy on neonatal health is of paramount importance given the known reductions in morbidities such as preeclampsia, diabetes, macrosomia, and cesarean delivery with limited weight gain in pregnancy. The goal of our study was to examine relationships between maternal BMI, IOMR categorizations, and fetal growth abnormalities in normal weight, overweight and obese women.

\section{Materials and Methods}

We conducted a retrospective cohort study of all women who delivered at the University of Cincinnati in 2008 and 2009. The study was approved by the institutional human subjects review committee. Subjects were included if they underwent live birth of a singleton pregnancy beyond 32 weeks of gestation and had a documented pre-pregnancy and delivery BMI. To increase accuracy of the baseline weight we excluded women who did not have a prenatal visit prior to 17 weeks, and used reported prepregnancy weight when the first visit was beyond 12 weeks. We excluded women who developed preeclampsia given associations of preeclampsia with both rapid maternal weight gain from fluid retention near delivery and impaired fetal growth. In addition, women who were underweight and those carrying a fetus with an anomaly that is associated with growth restriction were also excluded (Figure 1).

The primary analysis was a comparison between maternal weight gains in pregnancy in women who delivered fetuses with normal growth, SGA and LGA. SGA was defined as a birth weight less than the $10^{\text {th }}$ percentile, and LGA was defined as a birthweight over the $90^{\text {th }}$ percentile. The primary exposure studied was the difference in delta weight in women who went on to have newborns in these three study groups. The maternal delta weight change was calculated by subtracting the pre-pregnancy weight from the last recorded weight prior to delivery. ANOVA was used to compare mean maternal delta weight between outcome groups. A secondary analysis was performed in which women were categorized as to whether they met, exceeded or failed to meet the IOMR weight gain, stratified by their prepregnancy BMI classification. Subanalysis was performed in NW, OW and obese women separately and multivariate analysis was performed. Finally, we performed linear regression analyses comparing delta maternal weight change to birthweight grouped by maternal BMI class to compare the correlation coefficent and $r$ squared measures of the strength of correlation between these continuous variables in these individual populations.

Study data were collected and managed using Redcap electronic data capture tools posted at the University of Cincinnati. Categorical variables were compared using chi square analysis. Continuous variables were compared using ANOVA. A two-sided $\mathrm{p}<0.05$ or $95 \%$ confidence interval not inclusive of the null value 1.0 were considered statistically significant. Linear regression assessed the association between maternal delta weight change and the fetal birthweight with results reported as correlation coefficients and $\mathrm{r}$ squared values. Multivariate analysis compared the rates of these fetal growth outcome abnormalities in women according to their IOMR categorization based upon BMI class. Logistic regression models adjusted for potential confounding variables including race, tobacco use, pregestational diabetes, gestational diabetes and chronic hypertension with results presented as adjusted odds ratios with $95 \%$ confidence intervals. All data analysis was performed using NCSS 8 statistical software (Release 8. NCSS LLC, Kaysville, Utah).

\section{Results}

There were 4,569 deliveries in 2008 and 2009 at the University of Cincinnati. We excluded 1527 women from analysis because they did not present for prenatal care weight prior to 17 weeks (Figure 1). An additional 894 women were excluded because they met other exclusion criteria. The final cohort studied included 2148 women. Our subjects were clinically similar with respect to demographic characteristics such as age, gravidity and race in the three study groups (Table 2). In addition, although statistically different, the median gestational age at which subjects delivered was also clinically similar with the median gestational age at delivery being 38.5, 37.9 and 38.9 weeks in normal, SGA and LGA fetuses respectively $(\mathrm{p}<0.01)$. As would be expected, a higher rate of cesarean deliveries was seen in both SGA and LGA fetuses. In addition, as expected, higher rates of pregestational diabetes and gestational diabetes were seen in women with a LGA fetus. Tobacco use was higher in women with SGA fetuses.

There were 1792 (83.4\%), $223(10.3 \%)$ and 134 (6.2\%) of newborns that were normal, SGA and LGA respectively. The maternal delta weight change is clinically very similar between women with normal weight newborns and women with SGA newborns, 10.5 and $9.6 \mathrm{~kg}$ : however, women with LGA newborns have an increased mean maternal weight gain, $13.8 \mathrm{~kg}(\mathrm{p}<0.01)$.

The mean birth weight in women exceeding IOMR is higher (3358 gm) versus women who met IOMR or gained under IOMR (3169 and $3056 \mathrm{gm}$, respectively, $\mathrm{p}<0.01$ ) (Table 3 ). When women are categorized according to whether they met, exceeded or failed to meet IOMR weight gain we found associations between excessive weight gain and LGA in all BMI categories. When all women in our cohort are considered, women who met IOMR had a $9.7 \%$ rate of SGA as compared to $14.0 \%$ of women with weight gain under IOMR $(\mathrm{p}<0.01)$. However, this association is not seen in overweight women, 12 versus $10 \%$ rate of SGA in overweight women who met IOMR versus gained under IOMR respectively, aOR0.88 (0.61-1.23) ( $\mathrm{p}=0.58)$.

In obese women the rate of LGA is significantly higher when there is excessive weight gain, $12.1 \%$ of obese women that had weight gain over IOMR had an LGA fetus. Obese women had a higher rate of SGA when they gained under IOMR compared to when the met IOMR, 10.7 versus $5.0 \%$ respectively. However, obese women in general had lower rates of SGA in each IOM category as compared to all women or NW women. When adjusted for confounding variables, the rate of SGA was no longer significantly increased when obese women gained under IOMR, aOR1.43 (0.95-2.16). In addition, the rate of SGA in obese women with weight gain below IOMR was very similar to the baseline rate of SGA in our entire

\section{Total Deliveries, $\mathrm{n}=4569$}

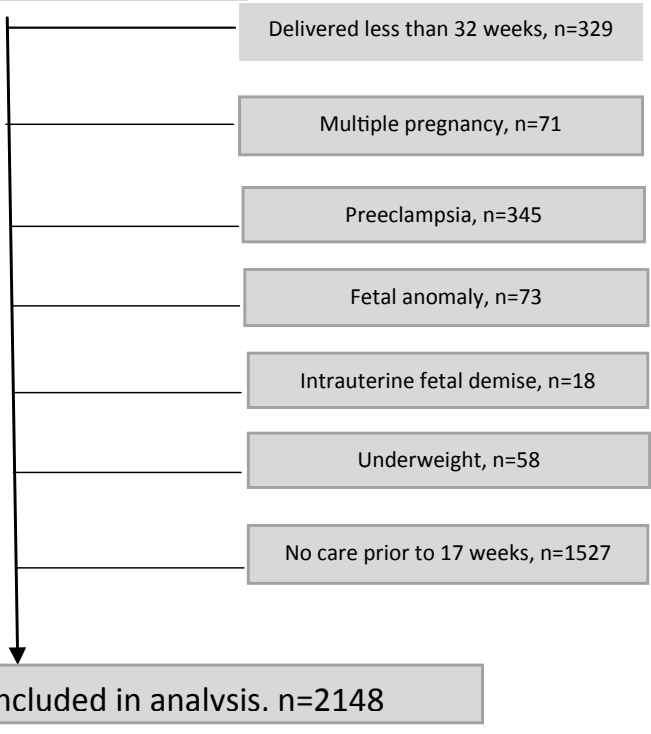

Figure 1: Flowchart of patients included and excluded from analysis. 


\begin{tabular}{|c|c|c|c|c|}
\hline \multirow{2}{*}{ Demographics } & Normal & SGA & LGA & \multirow{2}{*}{$p$ value } \\
\hline & $n=1791$ & $n=223$ & $n=134$ & \\
\hline Age, mean (SD) & $25(5.5)$ & $24(5.2)$ & $27(6.0)$ & 0.01 \\
\hline \multicolumn{5}{|l|}{ BMI classification, n (\%) } \\
\hline Normal weight & $697(83.5)$ & $109(13.0)$ & $30(3.6)$ & $<0.01$ \\
\hline Overweight & 485 (83.5) & $58(10.0)$ & $39(6.7)$ & \\
\hline Class 1 Obese & 309 (83.7) & $35(9.3)$ & $26(7.0)$ & \\
\hline Class 2 Obese & $158(83.6)$ & $9(4.8)$ & $23(11.8)$ & \\
\hline Class 3 Obese & 142 (83.5) & $12(5.4)$ & $16(12.1)$ & \\
\hline Gravidity, median (IQR) & $3(1,4)$ & $2(1,4)$ & $3(2,4)$ & 0.51 \\
\hline Race, n (\%) & & & & $<0.01$ \\
\hline Caucasian & $538(82.4)$ & $52(7.8)$ & $63(9.7)$ & \\
\hline African American & 947 (83.2) & $144(12.6)$ & $49(4.2)$ & \\
\hline Hispanic & $253(86.9)$ & $19(6.5)$ & $19(6.5)$ & \\
\hline Asian & $31(88.6)$ & $3(8.6)$ & $1(2.9)$ & \\
\hline Other & $22(75.9)$ & $5(17.2)$ & $2(6.9)$ & \\
\hline \multicolumn{5}{|l|}{ Delivery Information } \\
\hline Birth weight, mean (SD) & 3218 (418) & $2492(354)$ & $\begin{array}{l}4217 \\
(261)\end{array}$ & $<0.01$ \\
\hline $\begin{array}{l}\text { GA at delivery, median } \\
\text { (IQR) }\end{array}$ & $38.5(1.8)$ & $37.9(1.6)$ & $38.9(1.4)$ & $<0.01$ \\
\hline $\begin{array}{l}\text { Cesarean delivery, } \mathrm{n} \\
(\%)\end{array}$ & $501(28.0)$ & $70(31.5)$ & $60(45.1)$ & $<0.01$ \\
\hline \multicolumn{5}{|l|}{ Co-morbidities } \\
\hline $\begin{array}{l}\text { Pregestational DM, } n \\
(\%)\end{array}$ & $48(2.7)$ & $3(1.3)$ & $15(11.2)$ & $<0.01$ \\
\hline Gestational DM, n (\%) & $91(5.1)$ & $15(6.7)$ & $17(12.7)$ & $<0.01$ \\
\hline $\begin{array}{l}\text { Chronic hypertension, } \\
\text { n (\%) }\end{array}$ & $96(5.4)$ & $13(5.8)$ & $8(6.0)$ & 0.91 \\
\hline Tobacco use, n (\%) & $338(18.9)$ & $71(31.8)$ & $20(14.9)$ & $<0.01$ \\
\hline \multicolumn{5}{|l|}{ Maternal weight gain } \\
\hline Delta weight $(\mathrm{kg})$ & $10.5(6.6)$ & $9.6(6.5)$ & $13.8(7.2)$ & $<0.01$ \\
\hline \multicolumn{5}{|c|}{ All BMI Categories ( $n=2148), n(\mathrm{col} /$ row \%) } \\
\hline $\begin{array}{l}\text { Met IOM } \\
\text { recommendations }\end{array}$ & $541(30 / 86)$ & $\begin{array}{c}61 \\
(27 / 10)\end{array}$ & $26(19 / 4))$ & $<0.01$ \\
\hline $\begin{array}{l}\text { Under IOM } \\
\text { recommendations }\end{array}$ & $593(33 / 82)$ & $\begin{array}{c}101 \\
(45 / 14)\end{array}$ & $25(19 / 4)$ & \\
\hline $\begin{array}{l}\text { Exceeded IOM } \\
\text { recommendations }\end{array}$ & $657(37 / 82)$ & $61(27 / 8)$ & $\begin{array}{c}83 \\
(62 / 10)\end{array}$ & \\
\hline \multicolumn{5}{|l|}{$\begin{array}{l}\text { Overweight Women } \\
(n=581)\end{array}$} \\
\hline $\begin{array}{l}\text { Met IOM } \\
\text { recommendations }\end{array}$ & $153(32 / 85)$ & $\begin{array}{c}21 \\
(36 / 12)\end{array}$ & $6(15 / 3)$ & 0.07 \\
\hline $\begin{array}{l}\text { Under IOM } \\
\text { recommendations }\end{array}$ & $116(24 / 85)$ & $\begin{array}{c}14 \\
(24 / 10) \\
\end{array}$ & $7(18 / 5)$ & \\
\hline $\begin{array}{l}\text { Exceeded IOM } \\
\text { recommendations }\end{array}$ & $216(45 / 82)$ & $23(40 / 9)$ & $\begin{array}{c}26 \\
(67 / 10)\end{array}$ & \\
\hline \multicolumn{5}{|l|}{ Obese Women $(n=727)$} \\
\hline $\begin{array}{l}\text { Met IOM } \\
\text { recommendations }\end{array}$ & $158(26 / 88)$ & $9(16 / 5)$ & $13(20 / 7)$ & 0.02 \\
\hline $\begin{array}{l}\text { Under IOM } \\
\text { recommendations }\end{array}$ & $197(32 / 84)$ & $\begin{array}{c}25 \\
(45 / 11)\end{array}$ & $14(22 / 6)$ & \\
\hline $\begin{array}{l}\text { Exceeded IOM } \\
\text { recommendations }\end{array}$ & $254(42 / 81)$ & $22(39 / 7)$ & $\begin{array}{c}38 \\
(59 / 12) \\
\end{array}$ & \\
\hline
\end{tabular}

population, 10.6 vs $10.4 \%$, suggesting loss of a protective effect obesity offers for SGA as opposed to an actual increased risk from baseline when obese women gain less weight than IOMR. This also correlates with the definition of SGA as fetuses with a birth weight less than the $10^{\text {th }}$ percentile.

Finally, we performed a series of linear regression analyses to examine the relationship between the continuous variables maternal delta weight change and birthweight (Figure 3). We performed this analysis in all women, normal weight women, overweight women and obese women. The relationship between these continuous variables was, in general, weak for all categories and demonstrated a progressively weaker effect with increasing BMI classification, as defined by correlation coefficients of 0.21 (all BMI categories), 0.32 (normal weight), 0.25 (overweight), and 0.19 (obese).

\section{Discussion}

The obesity epidemic has reached the forefront in public health issues confronting our population. The effects of maternal weight gain in pregnancy on pregnancy outcomes, neonatal morbidities, maternal morbidities and long-term effects for both the mother and child are an area of active research. Excessive weight gain in pregnancy has deleterious effects on obstetrical outcomes, increasing maternal and neonatal morbidities [9]. In addition, maternal obesity and excessive weight gain has also been demonstrated to increase fetal macrosomia, putting infants at increased risk of childhood obesity and the "metabolic syndrome" [1923]. Some studies have linked excessive weight gain alone, even in normal weight and overweight women, to childhood obesity [24].

Women of reproductive age represent a uniquely targetable population to focus resources in the battle against obesity because of their increased access to medical care. In addition, pregnant women, in general, may feel tremendous pressure to gain weight that often emanates from their partners, families, friends, co-workers and even health care providers. At each prenatal visit women are weighed and confronted with their perceived success or failure on this front and whether intended or not, they are reminded of the need to gain weight. In addition, it is during their reproductive years that women can often go from being normal weight to overweight or even obese over the course of one or more pregnancies, often with minimal time intervening between pregnancies to revert to their prepregnancy weight, a cycle that has been demonstrated to increase the rate of subsequent development of type 2 diabetes [25]. Pregnancy also represents a unique opportunity for education and lifestyle interventions for otherwise healthy women who may have limited access to care or who may not otherwise obtain nutritional and exercise education. The ripple effect of educating young mothers regarding healthy lifestyle and dietary choices could be profound on both the adult and pediatric population [26].

In the past, there has been a reluctance to challenge the notion that pregnant women should gain a significant amount of weight, even in light of demonstrated improvements in obstetrical morbidities with limited weight gain $[12,13,27]$. The most pronounced concern has been the impact of limiting weight gain on the growth of the neonate. Many previous studies have demonstrated increasing rates of SGA with limited maternal weight gain [9,13-16]. While limited maternal weight gain may increase the rate of SGA, there is currently no evidence that limiting maternal weight gain in an otherwise healthy woman increases neonatal complications such as perinatal mortality or other severe complications in the neonatal period in either normal weight, overweight or obese women. Since SGA has been associated with several neonatal morbidities (including hypoglycemia, hyperbilrubininemia, hypothermia, intraventricular hemorrhage, necrotizing enterocolitis, seizures, sepsis, respiratory distress syndrome, and neonatal death) it is plausible that higher rates of SGA are likely to impact neonatal health $[26,28-30]$. However, whether SGA

Table 2: Demographic information, complications and outcomes in pregnancies by birth weight category: normal, SGA or LGA.

Citation: Magner K, Kritzer S, Warshak CR (2015) Examination of the Impact of Maternal Weight Gain on Abnormalities of Fetal Growth in Women of Varying Body Mass Indices. Obes Open Access 1(3): http://dx.doi.org/10.16966/2380-5528.112 
Open Access

\begin{tabular}{|c|c|c|c|c|c|c|c|c|}
\hline & Group 1 & Group 2 & & & Group 3 & & & \multirow{2}{*}{$p$ value } \\
\hline & $n=628$ & $n=719$ & OR $(95 \% \mathrm{CI})$ & aOR $(95 \% \mathrm{Cl})$ & $n=801$ & OR $(95 \% \mathrm{Cl})$ & aOR $(95 \% \mathrm{Cl})$ & \\
\hline \multicolumn{9}{|l|}{ All women } \\
\hline GA at delivery median(IQR) & $38(37,39)$ & $39(38,40)$ & & & $39(38,40)$ & & & $<0.01$ \\
\hline SGA, n (\%) & $61(9.7)$ & $101(14.0)$ & $1.23(1.04-1.46)$ & $1.12(1.02-1.44)$ & $61(7.6)$ & $0.87(0.72-1.05)$ & $0.86(0.72-1.37)$ & $<0.01$ \\
\hline \multicolumn{9}{|c|}{ Normal weight women $(n=836)$} \\
\hline Birth weight, mean (SD) & $3144(482)$ & $2967(504)$ & & & $3360(491)$ & & & $<0.01$ \\
\hline SGA, n (\%) & $31(11.6)$ & $62(17.5)$ & $1.29(1.02-1.62)$ & $1.26(0.99-1.61)$ & $16(7.2)$ & $0.77(0.56-1.06)$ & $0.75(0.54-1.04)$ & \\
\hline LGA, n (\%) & $7(2.6)$ & $4(1.2)$ & $0.66(0.36-1.23)$ & $0.72(0.37-1.40)$ & $19(8.6)$ & $1.86(1.20-2.91)$ & $1.87(1.20-2.93)$ & \\
\hline \multicolumn{9}{|l|}{ Overweight women $(n=581)$} \\
\hline \multicolumn{9}{|l|}{ Obese women $(n=727)$} \\
\hline Birth weight, mean (SD) & $3233(517)$ & $3173(539)$ & & & $3364(553)$ & & & $<0.01$ \\
\hline SGA, n (\%) & $9(5.0)$ & $25(10.7)$ & $1.51(1.02-2.24)$ & $1.43(0.95-2.16)$ & $21(6.7)$ & $0.86(0.57-1.28)$ & $1.23(0.82-1.86)$ & \\
\hline LGA, n (\%) & $13(7.2)$ & $13(5.6)$ & $0.87(0.58-1.29)$ & $0.77(0.50-1.20)$ & $38(12.1)$ & $1.33(0.96-1.85)$ & $1.36(0.96-1.92)$ & \\
\hline
\end{tabular}

Table 3: Relationship between maternal weight gain and rates of fetal growth abnormalities in NW, OW and obese women. Group 1: Met IOM recommendations, Group 2: Under IOM recommendations, Group 3: Exceeded IOM recommendations. Adjusted odds ratio controlled for race, tobacco use, pregestational diabetes, gestational diabetes and chronic hypertension.

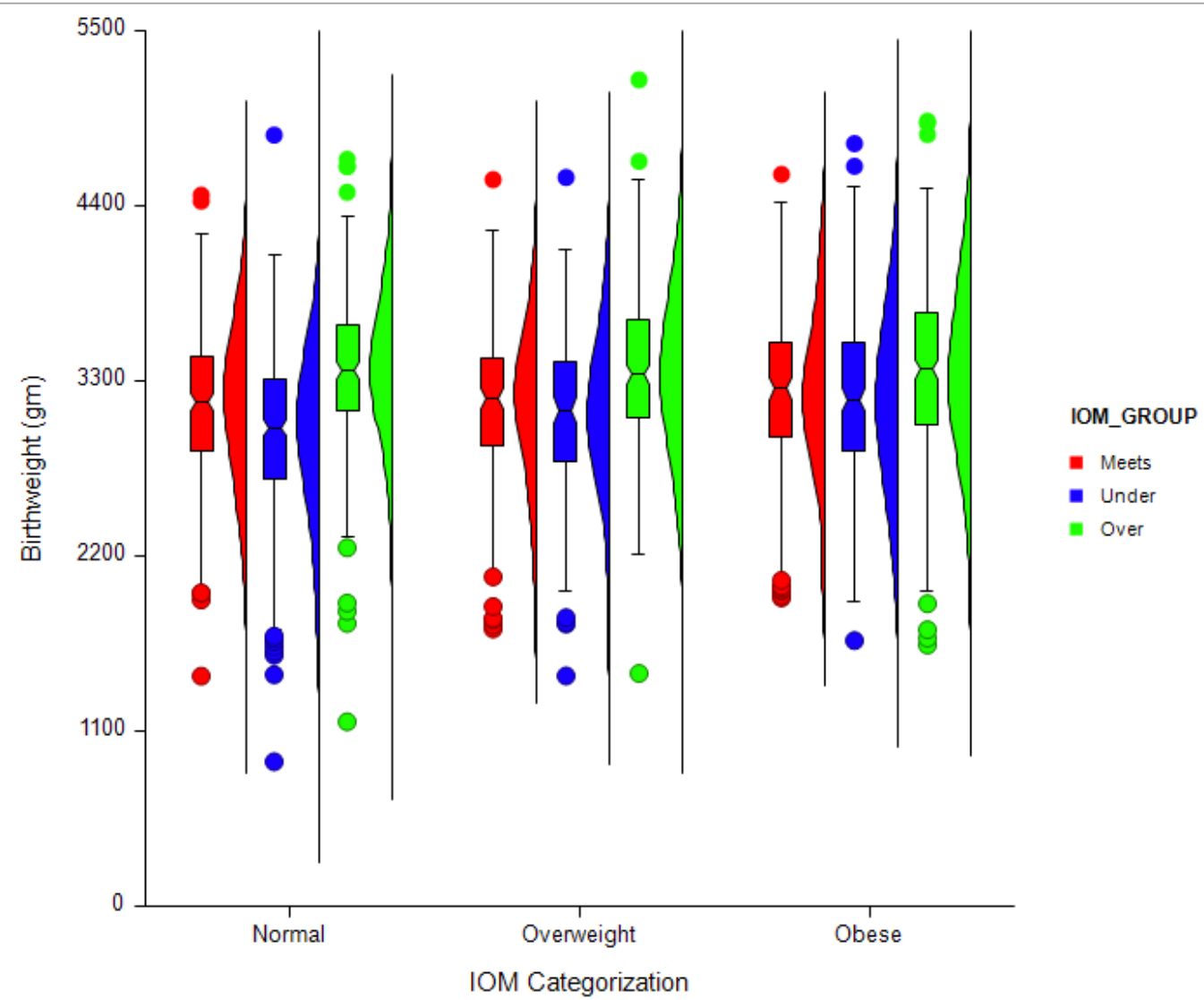

Figure 2: Distribution of birth weight by IOM Recommendation category and maternal BMI category. Boxplot demonstrates the median, $25^{\text {th }}$ and $75^{\text {th }}$ interquartile range, with whiskers to the $10^{\text {th }}$ and $90^{\text {th }}$ percentile.

Citation: Magner K, Kritzer S, Warshak CR (2015) Examination of the Impact of Maternal Weight Gain on Abnormalities of Fetal Growth in Women of Varying Body Mass Indices. Obes Open Access 1(3): http://dx.doi.org/10.16966/2380-5528.112 

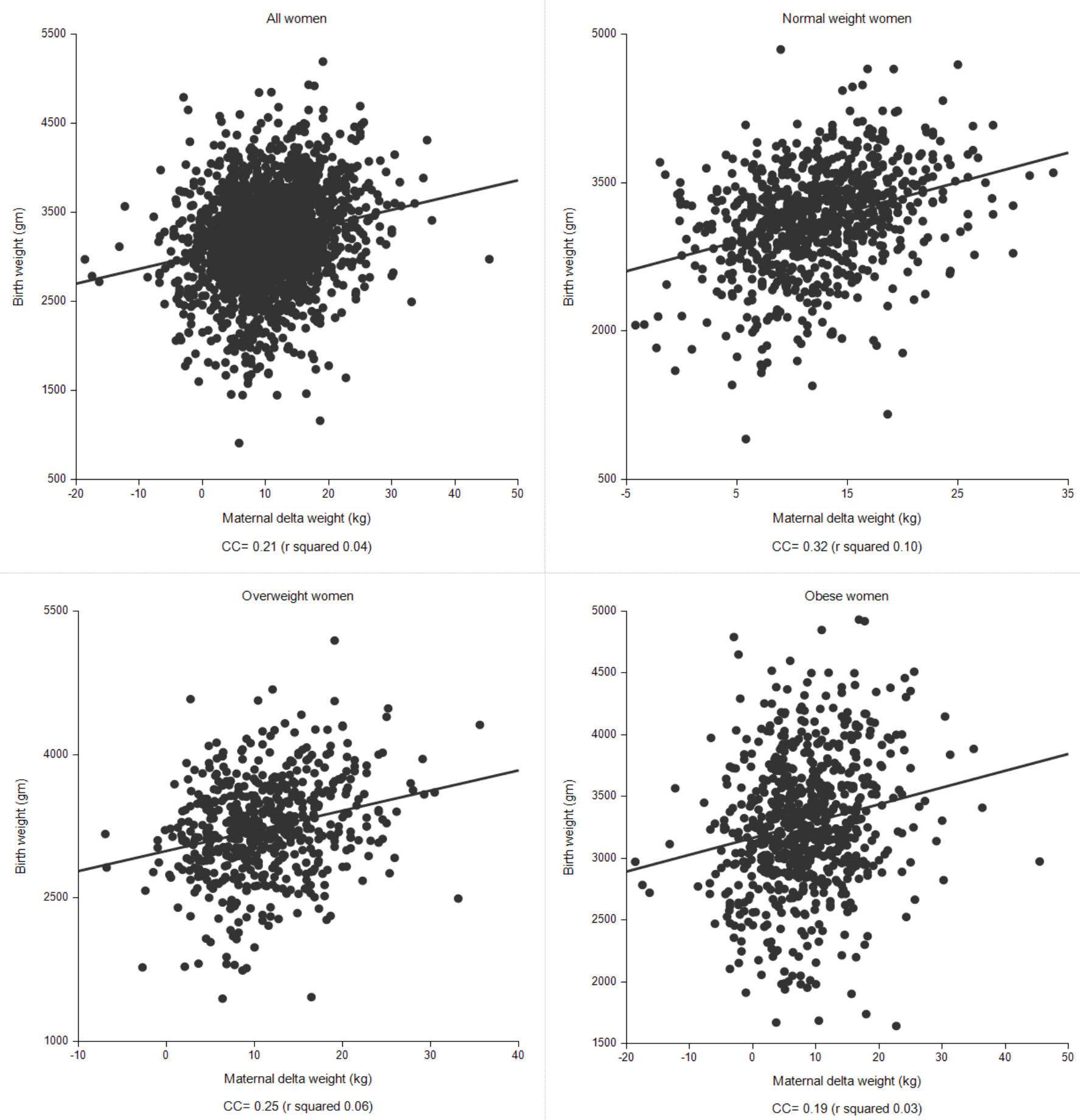

Figure 3: Linear regression analysis comparing maternal weight change and fetal birth weight in all, normal weight, over weight and obese women.

caused by limited maternal weight gain alone in otherwise healthy women (as opposed to settings of placental insufficiency, fetal abnormality, concurrent maternal co-morbidities, etc) also increases these actual fetal morbidities is unknown.

Although we saw a comparable mean maternal weight gain in women with SGA vs normal weight fetuses $(9.5 \mathrm{vs} 10.6 \mathrm{~kg})$, this study lends evidence to the belief that in normal weight women there may be a necessary minimal weight gain to reduce neonatal morbidity, atleast as measured by reducing the rate of SGA. Less is known about the impact of limiting maternal weight gain in overweight and obese women despite these women now comprising the majority in many populations. Our data provides evidence that not meeting IOMR does not significantly increase the rate of SGA in this specific population once other important confounders are considered. These results are quite similar to those of the recent NICHD MFMU Network study [9]. In this study, NW and obese women had higher rates of SGA, however overweight and underweight women did not. A key methodological difference between this study and ours was they included age, race, treatment group, and smoking in

Citation: Magner K, Kritzer S, Warshak CR (2015) Examination of the Impact of Maternal Weight Gain on Abnormalities of Fetal Growth in Women of Varying Body Mass Indices. Obes Open Access 1(3): http://dx.doi.org/10.16966/2380-5528.112 
their multivariate analysis while ours also accounted for diabetes and hypertension known to be increased in overweight and obese women, and also known to effect rates of SGA. In addition, the rates of SGA in the trial by Johnson were very high, $15.3 \%$ in women that met IOMR and even $10.7 \%$ in women who exceeded IOMR. It is unclear why they experienced higher than expected rates of SGA. In comparison to our population, a much smaller percentage of women gained under IOMR (9.5\% versus our rate of 33\%). The population in the NICHD study was $40.8 \%$ overweight and obese, unlike our study where the rate of overweight and obese was $61 \%$, possibly contributing to this difference. There were also differences in eligibility (nulliparous versus all) and methods to obtain prepregancy weight, etc. that may have contributed observed differences.

Finally, it should be noted that there are likely to be several immediate and long-term benefits to maternal health if limited weight gain is encouraged in overweight and obese women. The recent article by the NICHD reported lower rates of gestational hypertension, preeclampsia, cesarean delivery and LGA in women with recommended or lower than recommended weight gain [9]. Benefits such as these must be weighed against any perceived or real newborn risks before counseling women regarding the optimal amount of weight gain during their pregnancy.

There are many strengths to our study including the large cohort and the high rate of overweight and obesity that allowed us to examine these subsets of the population individually. Unlike most studies examining weight gain in pregnancy, we used only maternal weights obtained directly from the medical record in women who presented early for care, as opposed to birth certificate data or data from large databases in which the prepregnancy weight is generally self-reported at the end of pregnancy and therefore more likely to be erroneous. Although not perfect, as would be if all women had recorded a weight just prior to conception, the method in which we determined the baseline weight is most reflective of that seen in actual clinical practice. In addition, no prior studies have utilized a linear regression analysis to compare the continuous variables, delta maternal weight and birth weight.

Our most pronounced limitation is that we were unable to control for many other medical comorbidities, such as hyperemesis or substance abuse, which may have an exacerbating effect on the rate of poor fetal growth, especially in women with poor weight gain. Assuming this to be the case, limiting analysis to healthy women without other comorbidities such as these would be expected to reduce the rate of SGA, possibly even in women with limited weight gain and in normal weight women. Because we excluded women delivered prior to 32 weeks to reduce shortened gestation being a reason for limited weight gain, we were unable to comment in this study on effects of weight gain on rates of prematurity. In addition, this was not an interventional trial and effects of aggressive dietary education and lifestyle education modifications were not evaluated. Finally, our primary outcome measures were SGA and LGA. It should be noted these are not morbidities, per se, but surrogate markers for other morbidities. We would encourage further investigation into whether limited maternal weight gain increases the risks of actual neonatal morbidities such as those listed above.

In summary, we found in women who are overweight or obese the IOMR may overestimate the amount of weight gain necessary to reduce the rate of SGA from that in the baseline population, and that which would be expected by the definition of SGA. This is encouraging data that may facilitate physicians caring for pregnant women to encourage healthy diet and lifestyle modifications, with a lessened focus on maternal weight gain in women who are overweight and obese.

\section{Acknowledgements}

Study data were collected and managed with REDCap software which is hosted at Cincinnati Children's Hospital Medical Center under the Center for Clinical and Translational Science and Training grant support (UL1RR026314-01 NCRR/NIH). REDCap is a secure, web-based application that was designed to support data capture for research studies to provide (1) an intuitive interface for validated data entry, (2) audit trails for tracing data manipulation and export procedures, (3) automated export procedures for seamless data downloads to common statistical packages, and (4) procedures for importing data from external sources.

\section{Conflicts of Interest}

The authors report no conflicts of interest to report.

\section{References}

1. American Medical Association (2013) AMA Adopts New Policies on Second Day of Voting at Annual Meeting.

2. Flegal KM, Carroll MD, Kit BK, Ogden CL (2012) Prevalence of obesity and trends in the distribution of body mass index among US adults, 1999-2010. JAMA 307: 491-497.

3. Rasmussen KM, Yaktine AL (2009) Weight gain during pregnancy: reexamining the guidelines. The National Academies Press, Washington, DC.

4. Hedderson MM, Weiss NS, Sacks DA, Pettitt DJ, Selby JV, et al. (2006) Pregnancy weight gain and risk of neonatal complications: macrosomia, hypoglycemia, and hyperbilirubinemia. Obstet Gynecol 108: 1153-1161.

5. Durie DE, Thornburg LL, Glantz JC (2001) Effect of second-trimester and third-trimester rate of gestational weight gain on maternal and neonatal outcomes. Obstet gynecol 118: 569-575.

6. Atral R, Lockwood CJ, Brown HL (2010) Weight gain recommendations in pregnancy and the obesity epidemic. Obstet Gynecol 115: 152-155.

7. Gaillard R, Durmus B, Hofman A, Mackenback JP, Steegers EA, et al. (2013) Risk factors and outcomes of maternal obesity and excessive weight gain during pregnancy. Obesity (Silver Spring) 21: 1046-1055.

8. Carreno CA, Clifton RG, Hauth JC, Myatt L, Roberts, JM, et al. (2012) Excessive early gestational weight gain and risk of gestational diabetes mellitus in nulliparous women. Obstet gynecol 119: 1227-1233.

9. Johnson J, Clifton RG, Roberts JM, Myatt L, Hauth JC, et al. (2013) Pregnancy outcomes with weight gain above or below the 2009 Institute of Medicine Guidelines. Obstet Gynecol 121: 969-975.

10. de la Torre L, Flick AA, Istwan N, Rhea D, Cordova Y, et al. (2011) The effect of new antepartum weight gain guidelines and prepreganncy body mass index on the development of pregnancy-related hypertension. Am J Perinatol 28: 285-292.

11. Cedergren Ml (2004) Maternal morbid obesity and the risk of adverse pregnancy outcome. Obstet Gynecol 103: 219-224.

12. Saldana TM, Siega-Riz AM, Adair LS, Suchindran C (2006) The relationship between pregnancy weight gain and glucose tolerance status among black and white women in central North Carolina. Am J Obstet Gynecol 195: 1629-1635.

13. Kiel DW, Dodson EA, Atral R, Boehmer TK, Leet TL (2007) Gestational weight gain and pregnancy outcomes in obese women: how much is enough? Obstet Gynecol 110: 752-758.

14. Cnattingius S, Bergstrom R, Lipworth L, Kramer MS (1998) Prepregnancy weight and the risk of adverse pregnancy outcomes. $\mathrm{N}$ Engl J Med 333: 147-152.

15. Abrams BF, Laros RK Jr (1986) Prepregnancy weight, weight gain and birth weight. Am J Obstet Gynecol 154: 503-509.

16. Nohr EA, Vaieth M, Baker JL, Sorensen T, Olsen J, et al. (2008) Combined associations of prepregnancy body mass index and gestational weight gain with the outcome of pregnancy. Am J Clin Nutr 87: 1750-1759. 
17. Vesco KK, Sharma AJ, Dietz PM, Rizzo JH, Callaghan WM, et al. (2011) Newborn size among obese women with weight gain outside the 2009 Institute of Medicine recommendations. Obstet Gynecol 117: 812-818.

18. Bodnar LM, Siega-Riz AM, Simhan HN, Himes KP, Abrams B (2010) Severe obesity, gestational weight gain, and adverse birth outcomes. Am J Clin Nutr 91: 1642-1648.

19. Barker DJ (2006) Adult consequences of fetal growth restriction. Clin Obstet Gynecol 49: 270-283.

20. Weiss JL, Malone FD, Emig D, Ball RH, Nyberg DA, et al. (2004) Obesity, obstetric complications and cesarean delivery rate- a population-based screening study. Am J Obstet Gynecol 190: 10911097.

21. Phelan S (2010) Pregnancy: a "teachable moment" for weight control and obesity prevention. Am J Obstet Gynecol 202: 135.e1-e8.

22. von Kries $R$, Chmitorz $A$, Rasmussen KM, Bayer $O$, Ensenauer $R$ (2013) Late pregnancy reversal from excessive gestational weight gain lowers risk of childhood overweight: a cohort study. Obesity (Silver Spring) 21: 1232-1237.

23. Simmons $R$ (2008) Perinatal programming of obesity. Semin Perinatol 32: $371-374$
24. Hinkle SN, Sharma AJ, Swan DW, Schieve LA, Ramakrishnan U, et al. (2012) Excess gestational weight gain is associated with child adiposity among mothers with normal and overweight prepregnancy weight status. J Nutr 142: 1851-1858.

25. Whiteman VE, Aliyu MH, August EM, McIntosh C, Duan J, et al. (2011) Changes in prepregnancy body mass index between pregnancies and risk of gestational and type 2 diabetes. Arch Gynecol Obstet 284: 235240.

26. American College of Obstetricians and Gynecologists (2013) ACOG Practice bulletin no. 134: fetal growth restriction. Obstet Gynecol 121: 1122-1133.

27. Cedegren M (2006) Effects of gestational weight gain and body mass index on obstetric outcome in Sweden. Int J Gynaecol Obstet 93: 269274.

28. Resnik R (2002) Intrauterine growth restriction. Obstet Gynecol 99: 490-496.

29. Pallotto EK, Kilbride HW (2006) Perinatal outcomes and later implications of intrauterine growth restriction. Clin Obstet Gynecol 49: 257-269.

30. Lee PA, Chernausek SD, Hokken-Koelega AC, Czernichow P (2003) International Small for Gestational Age Advisory Board consensus development conference statement: management of short children born small for gestational age. Pediatrics 111: 1253-1261. 